Article

\title{
Determination of Layers Responsible for Rutting Failure in a Pavement Structure
}

\author{
Nathan Chilukwa ${ }^{1, *}$ and Richard Lungu ${ }^{2}$ \\ 1 Department of Civil Engineering and Construction, Copperbelt University, Kitwe 21692, Zambia \\ 2 Graduate of Civil Engineering, Copperbelt University, Kitwe 21692, Zambia; richardlungu03@gmail.com \\ * Correspondence: chilukwa2008@yahoo.com or nathan.chilukwa@cbu.ac.zm
}

Received: 11 February 2019; Accepted: 22 May 2019; Published: 26 May 2019

\begin{abstract}
Rutting is one of the most common distresses in asphalt pavements in Zambia. The problem is particularly prevalent at intersections, bus stops, railway crossings, police checkpoints, climbing lanes and other heavily loaded sections, where there is deceleration, slow moving or static loading. The most widely used methods to identify the source of rutting among flexible pavement layers are destructive methods; field trenching and coring methods. The Transverse Profile Analysis method (TPAM), which is a non-destructive method, was suggested by White et al. in 2002 as an alternative method, to avoid the expensive and destructive nature of the traditional methods. In this method, data from the transverse profile of the rutted section is used to deduce the layer of the pavement structure responsible for rutting failure. This study used the TPAM to determine the layers of pavement responsible for rutting on sections of the Chibuluma and Kitwe-Chingola Roads in Zambia. The method was first validated using the trenching method on the Kitwe-Ndola Road. Results from the TPAM showed good comparability with those from the trenching method. It was established that most of the rutting emanated from the surfacing layer. This is consistent with recent research indicating that most rutting occurs in the upper part of the asphalt surfacing. It was also established that the TPAM was a simpler, faster and less costly method of determining the source of rutting failure compared to the traditional methods.
\end{abstract}

Keywords: transverse profile analysis; rutting; asphalt; trenching; coring

\section{Introduction}

Zambia is a key transit country in the north-south corridor as it sits between and borders eight countries in the region, viz. Tanzania, the Democratic Republic of Congo, Botswana, Namibia, Zimbabwe, Mozambique, Angola and Malawi. With a virtually non-functional rail system, various mining products and equipment are transported in and out of the mines in the Copperbelt Province to South Africa, Tanzania and other countries in the region mostly by road.

Zambia has a total gazetted road network of $67,671 \mathrm{~km}, 40,454 \mathrm{~km}$ of which comprises the Core Road Network (CRN). The CRN is defined as the bare minimum network that Zambia requires to be maintained continuously and on a sustainable basis to realize its social and economic potential. The CRN infrastructure in Zambia consists of a sparsely interconnected network of Trunk (T), Main (M), District (D), Primary Feeder (PF) and Urban (U) roads. Table 1 shows the breakdown of the CRN in Zambia [1].

The traffic growth rate on major highways, in particular the truck traffic, has been increasing day by day in Zambia due to its geostrategic location and international trade corridor, subsequently leading to the premature failure of roads [2]. A recent study on the condition of the roads showed that as of 2014, less than $25 \%$ of the CRN was paved, and close to half of the paved road network was in a fair to poor condition [1]. 
Table 1. Zambia's Core Road Network (CRN) (2014).

\begin{tabular}{cc}
\hline Road Category & Core Road Network $(\mathbf{k m})$ \\
\hline Trunk (T) & 3116 \\
Main (M) & 3701 \\
District (D) & 13,707 \\
Urban (U) & 5597 \\
Primary Feeder (PF) & 14,333 \\
\hline Total & 40,454 \\
\hline
\end{tabular}

One of the most prominent defects, particularly on major highways, is rutting failure [2]. This type of failure is prominent in sections where traffic is forced to stop or move at a slow pace, thereby increasing the loading on the road pavement. Thus, the failure is load-related and it eventually escalates to include other defects such as cracking, potholing, etc.

Rutting is defined as a longitudinal surface depression occurring in the wheel paths of roadways due to repeated traffic loading. It accumulates incrementally with small permanent deformations from each load application over the pavement's service life. It is often followed in later stages by an upheaval along the sides of the rut. The decreased thickness in the rutted portions may accelerate fatigue cracking and eventual loss of the surfacing [3]. Rut depth (RD) is one of the most commonly used index variables for quantifying pavement surface rutting. This index has been traditionally measured manually, using a gauge with either a straightedge or a wire. The method is considered "a reliable and low budget option" [4].

Rutting failure not only reduces the lifespan of the road but is also a serious safety issue for road users. When the vehicle moves along the rutted portion of the pavement, steering becomes difficult and it reduces driving comfort. If rainwater pools in the rutted wheel path, it can result in hydroplaning and spray that reduces visibility. To this extent, rutting has become such a serious problem of modern-day roads that countries such as the United States have taken it as one of the design criteria for asphalt pavements [5].

Most Zambian roads are constructed of flexible pavements. Flexible pavements are roads constructed of several layers of natural or treated granular material covered with one or more waterproof bituminous surface layers (e.g., asphalt). They are so named because the total pavement structure deflects or flexes under loading. The objective with the design of a flexible pavement is to avoid the excessive flexing of any layer, the failure of which will result in the over-stressing of the layer, which ultimately will cause the pavement to fail [6].

The layer(s) in which rutting occurs is influenced by the loading magnitude and the relative strengths of the pavement layers. Stresses within the layer of a pavement structure are determined by applied load, individual and combined layer thickness and layer material properties [7].

The Mechanistic-Empirical Design Guide (MEPDG) has defined three distinct stages for the permanent deformation behavior of asphalt pavements under a given set of material, load and environmental conditions. This is shown in Figure 1 [5]. The primary stage has a high initial level of rutting, with a decreasing rate of plastic deformation, predominantly associated with volumetric change. The secondary stage has a small rate of rutting, exhibiting a constant rate of change of rutting that is also associated with volumetric changes; however, shear deformations increase at an increasing rate. The tertiary stage has a high level of rutting predominantly associated with plastic (shear) deformations under no volume change conditions. 


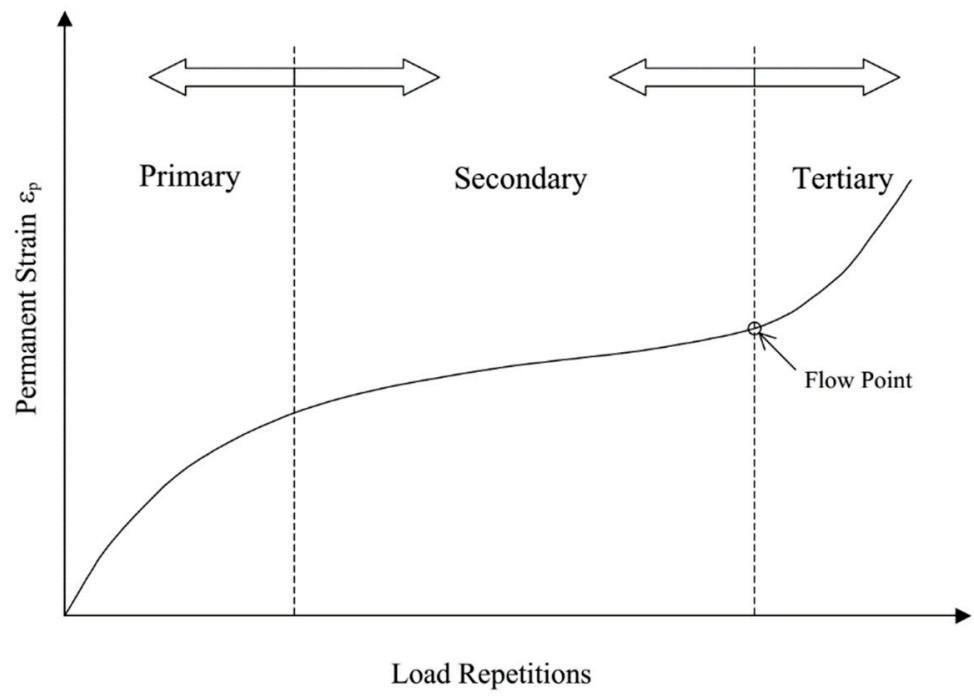

Figure 1. Typical repeated load permanent deformation behavior of pavement materials.

Generally, there are two causes of rutting in asphalt pavements-the accumulation of permanent deformation in the asphalt-surfacing layer and the permanent deformation of subgrade or underlying layers. In the past, subgrade deformation was considered the primary cause of rutting and many pavement design methods applied limiting criteria on vertical strain at the subgrade level. However, recent research has indicated that most of the rutting occurs in the upper part of the asphalt surfacing layer. Nonetheless, these two causes of rutting can act in combination, i.e., the rutting could be the sum of permanent deformation in all the layers [2,8,9].

The determination of which layer in the pavement structure is responsible for rutting failure is the first step toward arriving at a remedial measure.

The destructive methods of trenching and coring have traditionally been used for rutting failure investigations. Field trenching is conducted to expose the layers of the pavement so that they can be studied. The thickness of the layers, i.e., asphalt, the base and the subbase, are measured and plotted to show the deflections in the layers. Alternatively, core samples can be obtained at a constant spacing on a lane to determine the layer thicknesses of the pavement layers and the results can be plotted (similar to trenching) to determine the contribution of each layer to rutting due to changes in thickness and deflections of the pavement layers. The Dynamic Cone Penetrometer (DCP) Test has also been used to determine the strength of the pavement layers by calculating the California Bearing Ratio (CBR) of the pavement layers. The knowledge of the strengths of the existing pavement layers at a rutted section of the road can be used to deduce whether the ruts have been caused by weak structural layers, the subgrade or whether it is restricted to the surface. These methods are, however, time consuming and costly and may lead to weaknesses in the pavement structure if not repaired properly.

TPAM is one of the non-destructive techniques developed to determine the source of rutting in a pavement structure. The method was suggested by White et al. [7], who conducted extensive computer analyses using Finite Element Methods (FEM) to simulate rutting failures in Hot-Mix-Asphalt (HMA) surface mixtures, base courses and subgrades. Transverse surface profile characteristics indicative of failure within specific structural layers were then determined in the form of simple distortion parameters, and specific criteria were developed for these distortion parameters. The criteria were applied to an analysis of full-scale accelerated pavement test (APT) data, confirming that the relative contributions of the layers to rutting in an HMA pavement could be determined from an analysis of its transverse surface profile. This followed works such as [10], wherein the authors hypothesized that the area under the transverse surface profile could be used to predict the source of rutting from within the pavement structure. The authors of [11] also suggested that quantifying transverse profile 
measurements presented a potential method of determining the cause of rutting in the absence of traffic, structural and environmental data.

Another study [12] found that TPAM is one of the most accurate and precise methods of establishing the cause of rutting failure. The study used trenching, coring and Falling Weight Deflectometer (FWD) tests to validate the method. The authors of [13] also used the TPAM to determine the source of rutting failure on a $300 \mathrm{~m}$ section of the N5 National Highway in Pakistan. The study determined that most rutting was mainly due to the shear failure of the HMA layer. It was also observed that an increase in rut depth resulted in an increase in negative area and a reduction in positive area of the profile. The results were validated using the trenching method.

The TPAM was also used to determine the source of rutting on the Belbis-Zagazig Road in Egypt. A study determined that $60 \%$ of the rutting resulted from the HMA, $30 \%$ from the base layer and $10 \%$ from the subgrade. The authors concluded that the TPAM proved to be a good diagnostic tool for determining the source of most of the rutting failure [14].

The goal of this publication is to highlight the results of a study undertaken to establish the layer(s) responsible for rutting failure using the TPAM on some selected sections of road in the Copperbelt Province of Zambia.

The traditional methods of coring and trenching are the most commonly used methods of determining the source of rutting failure. However, these two methods are destructive, in that the subsurface layers must be exposed by excavating a trench or coring and then restored after rut investigations. This may lead to weaknesses at the joints, resulting in the shortening of the lifespan of the pavement if not repaired properly. Furthermore, these destructive methods are time-consuming, costly and inconveniencing to road users.

TPAM has been suggested as a simple yet effective way of determining the rutting failure source within the pavement structure through theoretical and analytical analyses of surface profiles, with little to none of the challenges associated with trenching and/or coring.

\section{Materials and Methods}

A typical transverse profile is shown in Figure 2. The method of analysis with the TPAM is explained below.

The first and last points of the profile line are joined to establish a reference line (indicated by the dotted line). The portion of the area above the line is considered as positive area $\left(\mathrm{A}_{\mathrm{p}}\right)$ and the portion below the reference line is considered as negative area $\left(A_{n}\right)$. The maximum rut depth $(D)$ is computed by firstly drawing a line joining the high points of the profile known as the wire line; the maximum rut depth is then equal to the line with the maximum length drawn between the profile line and the wire line in a direction perpendicular to the wire line.

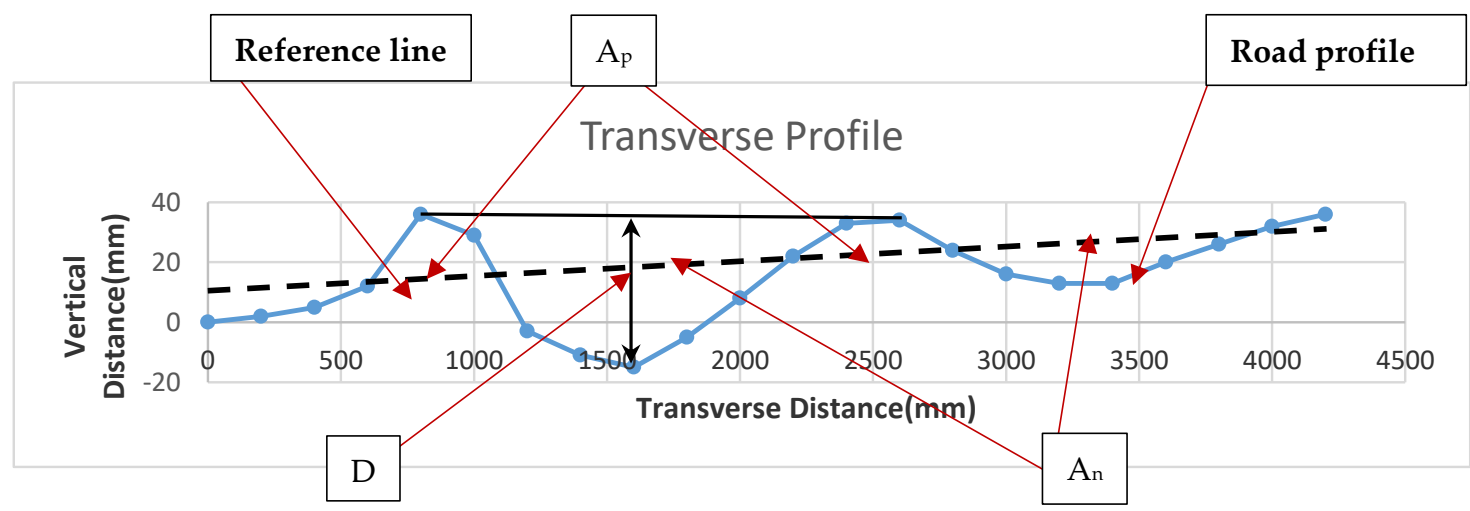

Figure 2. Plot of transverse profile from the edge of a shoulder to the center line of a lane. $A_{p}=$ area above dotted line; $A_{n}=$ area below dotted line; $\mathrm{D}=$ maximum rut depth. 
The positive and negative areas are calculated by plotting the profile to scale in AutoCAD or other software.

The distortion parameters, i.e., the total area, termed 'distortion' and the ratio of the positive or negative area to the total area, termed 'ratio of distortion' are computed by the following equations [7].

$$
\begin{gathered}
A=A_{p}+A_{n} \\
R=A_{p} / A_{n}
\end{gathered}
$$

where

$$
\begin{aligned}
& \mathrm{A}=\text { total area }\left(\mathrm{mm}^{2}\right) \\
& \mathrm{R}=\text { ratio of area; } \\
& \mathrm{A}_{\mathrm{p}}=\text { positive area }\left(\mathrm{mm}^{2}\right) \\
& \mathrm{A}_{\mathrm{n}}=\text { negative area }\left(\mathrm{mm}^{2}\right) .
\end{aligned}
$$

In predicting the layer responsible for rutting distress, it is also necessary to compute some critical coefficients by the following equations:

$$
\begin{aligned}
& C_{1}=(-858.21) D+667.58 \\
& C_{2}=(-1509) D-287.78 \\
& C_{3}=(-2120) D-407.95
\end{aligned}
$$

where

$\mathrm{C}_{1}=$ theoretical average total area for HMA failure $\left(\mathrm{mm}^{2}\right)$;

$\mathrm{C}_{2}=$ theoretical average total area for base/subbase failure $\left(\mathrm{mm}^{2}\right) ;$

$\mathrm{C}_{3}=$ theoretical average total area for subgrade failure $\left(\mathrm{mm}^{2}\right)$;

$\mathrm{D}=$ maximum rut depth $(\mathrm{mm})$.

These equations are called equations of trend lines for HMA, base and subgrade failure modes in failure criteria.

Based on the characteristics of a given surface profile and the criteria described above, the mode of failure can be inferred [7] as follows:

1. Failure has occurred in the HMA layer if both the following conditions are satisfied:

$$
\begin{gathered}
\mathrm{R}>0.05 \\
\mathrm{~A}>\left(\mathrm{C}_{1}+\mathrm{C}_{2}\right) / 2
\end{gathered}
$$

2. Failure has occurred in the base/subbase layer if both the following conditions are satisfied:

$$
\mathrm{R}<0.05
$$

$$
\mathrm{A}>\left(\mathrm{C}_{2}+\mathrm{C}_{3}\right) / 2
$$

3. Subgrade failure has occurred if no failure can be determined from the previous comparisons.

The method of analysis is summarized in the flow chart shown in Figure 3. 


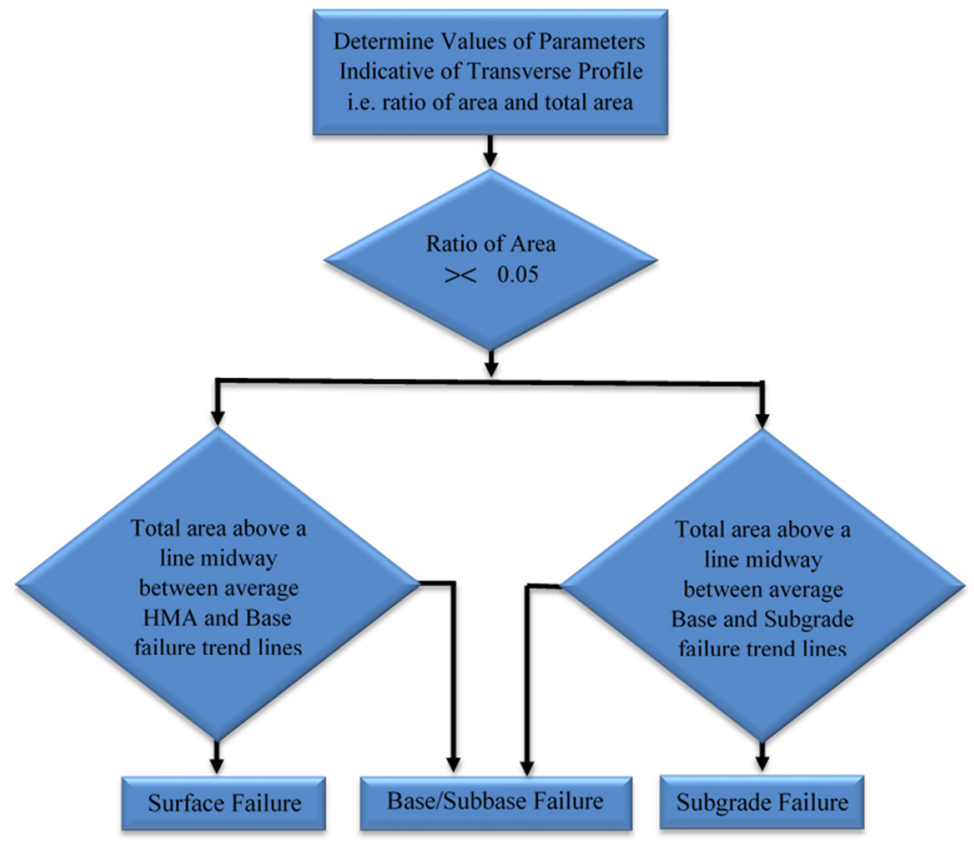

Figure 3. Illustration of the procedure for failed layer prediction [15].

A visual condition survey was undertaken to identify and select road pavements exhibiting rutting failure that were thus suitable for investigation. Three roads were selected, namely Kitwe-Ndola Road, Kitwe-Chingola Road and Chibuluma Road, all within the Copperbelt Province of Zambia.

\subsection{Kitwe-Ndola Road}

On the Kitwe-Ndola Road, the TPAM and trenching were conducted on a selected rutted section. The results of the profile analysis were compared to the trenching method for purposes of validation.

The pavement transverse profile was analyzed by measuring rut depths on a heavily rutted section of the road. This was done using the straight edge and gauge method. Four measurements were taken every $15 \mathrm{~m}$ on the rutted section. Profile measurements were taken at intervals of $200 \mathrm{~mm}$ from the shoulder edge to the center line of a lane. Four trenches were excavated at each point where a profile analysis was conducted. The excavation was done from the edge of the shoulder to the center line of a lane. The thickness of the asphalt and underlying layers were measured at intervals of $200 \mathrm{~mm}$ equal to the spacing used for rut depth measurements.

Figures 4-7 show the straight edge and gauge measurements and trench measurements on the Kitwe-Ndola Road.

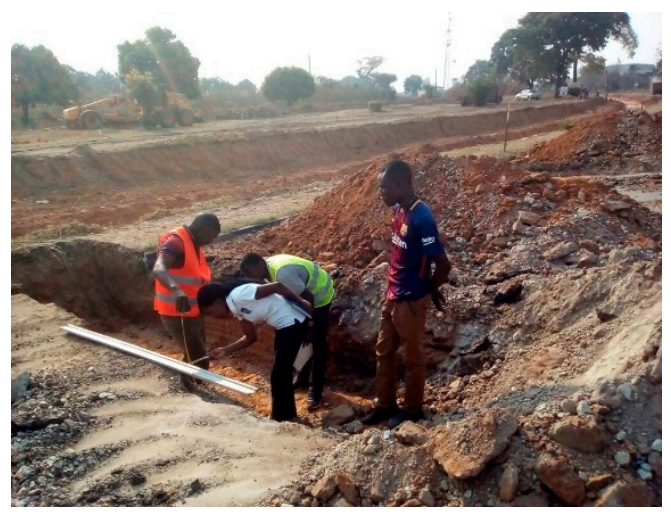

Figure 4. Trench measurements of Pit 1 (Kitwe-Ndola). 


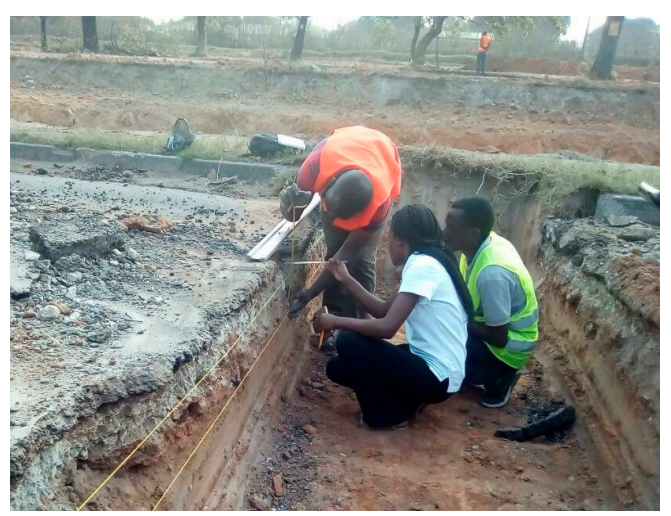

Figure 5. Trench measurements of Pit 2 (Kitwe-Ndola).

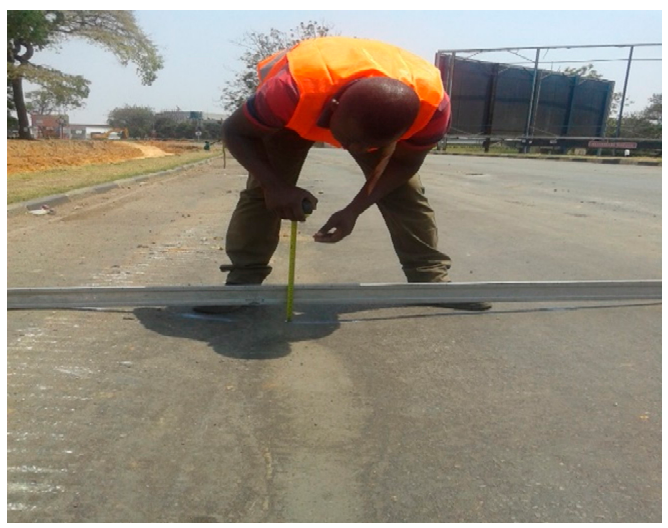

Figure 6. Profile measurements on Kitwe-Ndola Road.

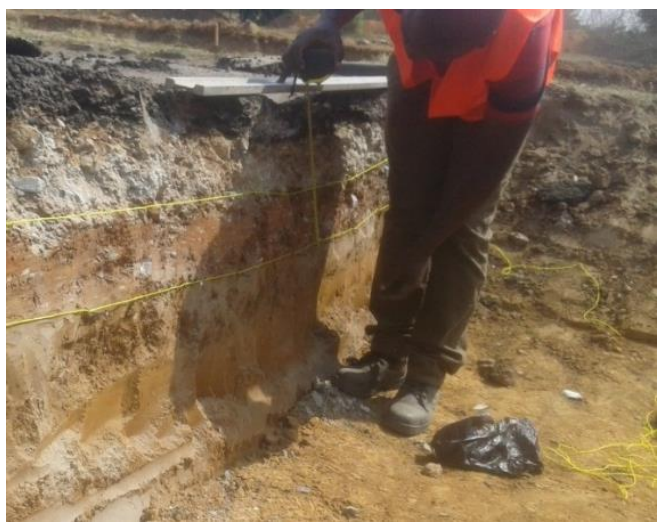

Figure 7. Trench measurements of Pit 3 (Kitwe-Ndola).

\subsection{Chibuluma Road and Kitwe-Chingola Road}

After the validation, assessments were also conducted on the Chibuluma and Kitwe-Chingola Roads. The TPAM was undertaken on an approximately $800 \mathrm{~m}$ section of the Chibuluma Road and a $135 \mathrm{~m}$ section of the Kitwe-Chingola Road to predict the layer(s) responsible for rutting failure.

The two roads were chosen due to the high levels of traffic and the high degree of rutting on the selected sections (see Figures 8 and 9). Chibuluma Road is used by heavy traffic to bypass the central business district of Kitwe, while Kitwe-Chingola Road is a key route connecting the two towns and goes further to the Kasumbalesa border and the mining region of the northwestern province. The two roads are interconnected somewhat, in that the heavy traffic that passes through Chibuluma Road eventually uses Kitwe-Chingola Road to connect to the Kasumbalesa border or the northwestern 
province. A recent study found that the traffic levels on the two roads averaged over 35 million equivalent standard axles.

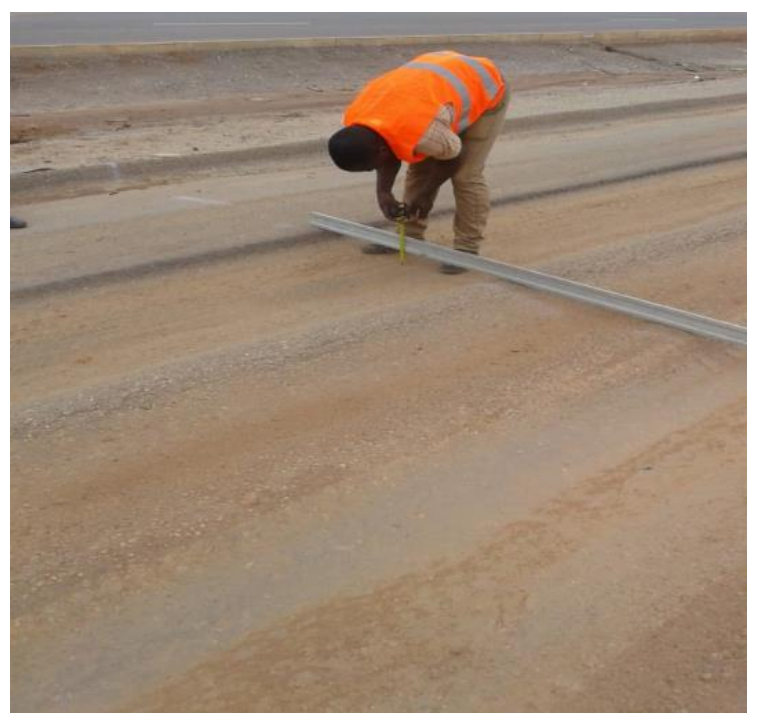

Figure 8. Profile measurements (Chibuluma).

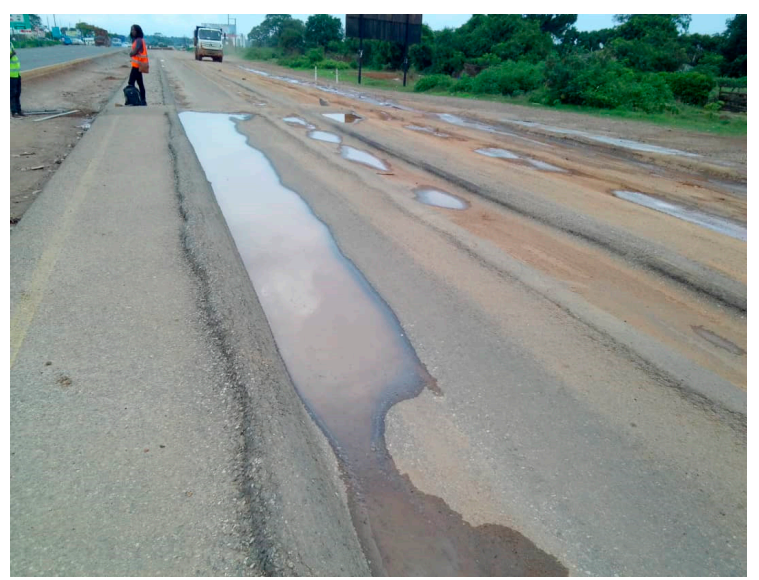

Figure 9. Extent of rutting (Kitwe-Chingola).

\section{Results}

\subsection{Validation of Kitwe-Ndola Road}

Results of the measurements after profile analysis and field trenching at Chainages; $60+365$, $60+427,60+437$ and $60+487$ of Kitwe-Ndola Road are shown in Figures 10-17.

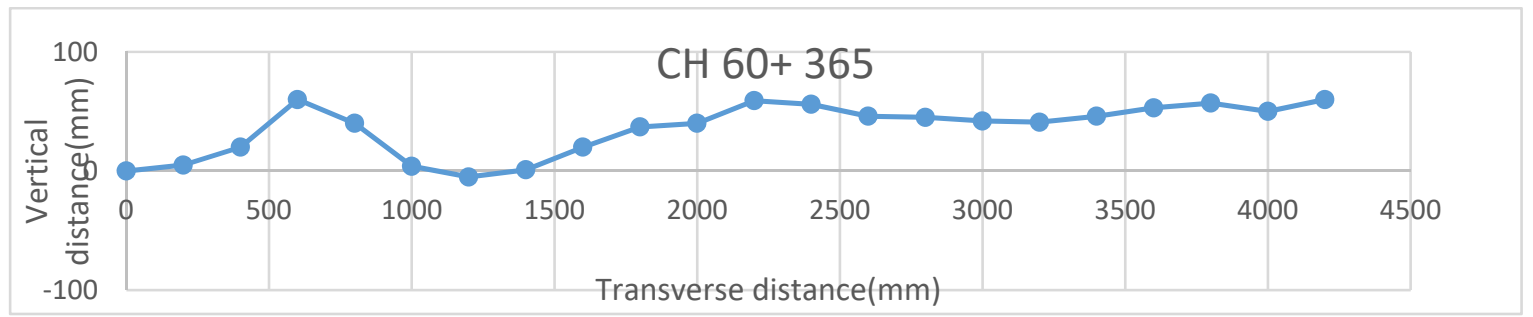

Figure 10. Transverse profile of $60+365 \mathrm{~km}$. 


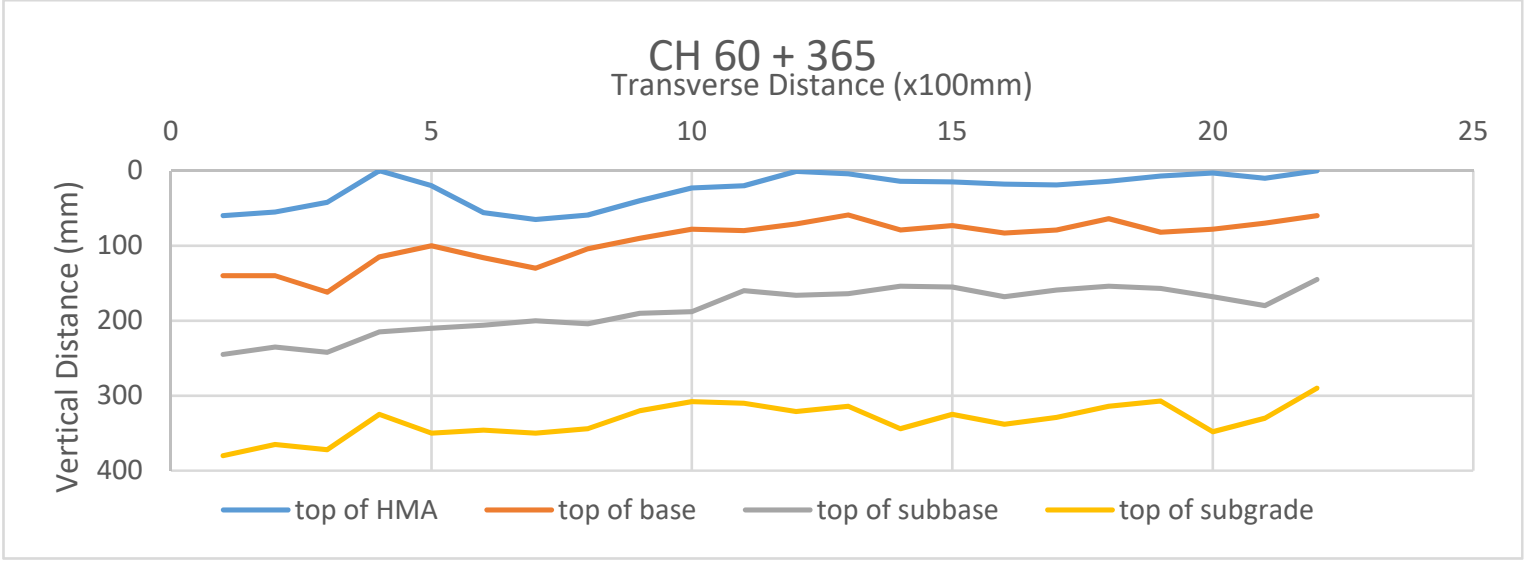

Figure 11. Profile of trench measurements of $60+365 \mathrm{~km}$.

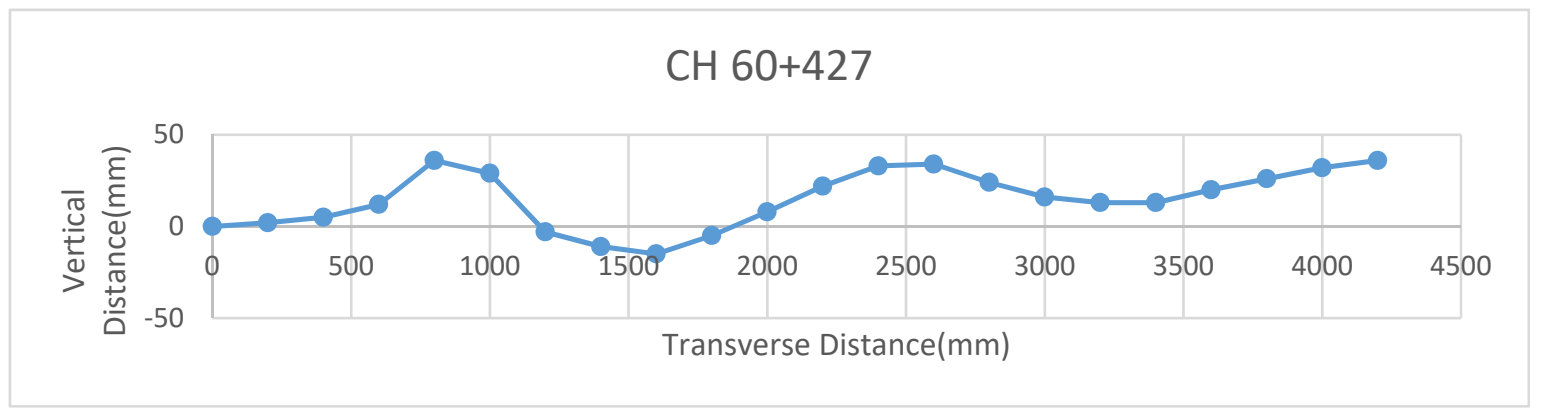

Figure 12. Transverse profile of $60+427 \mathrm{~km}$.

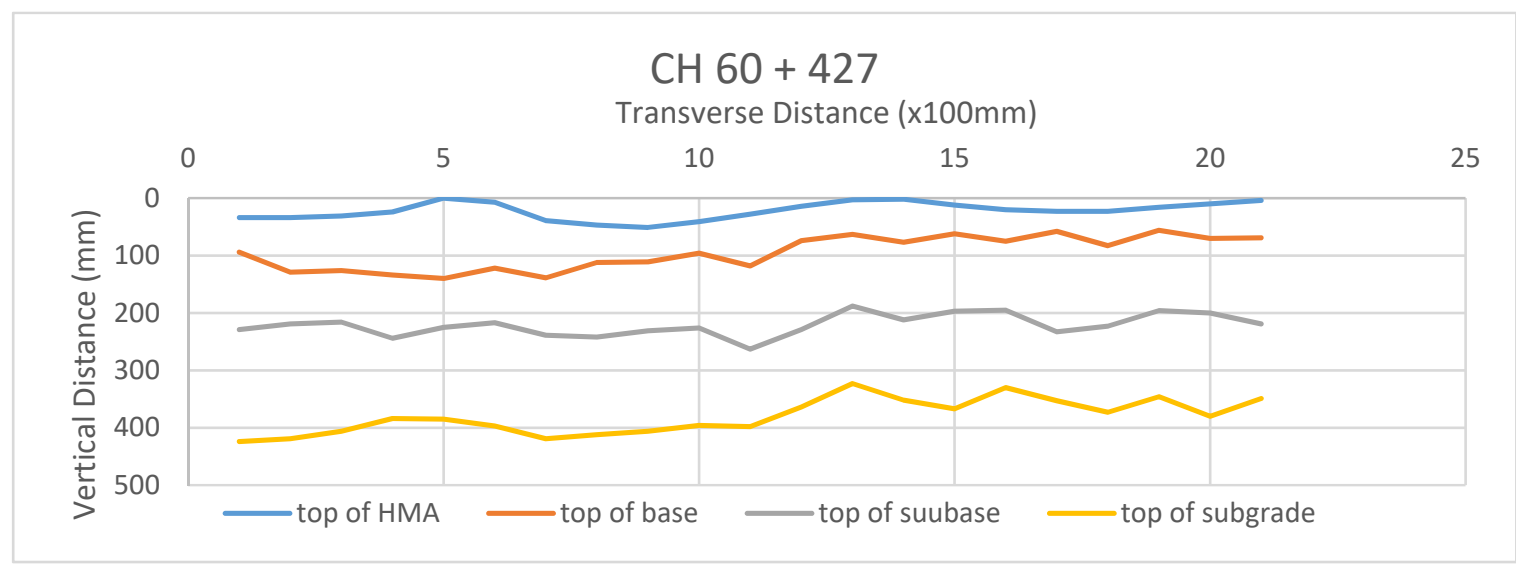

Figure 13. Profile of trench measurements of $60+427 \mathrm{~km}$.

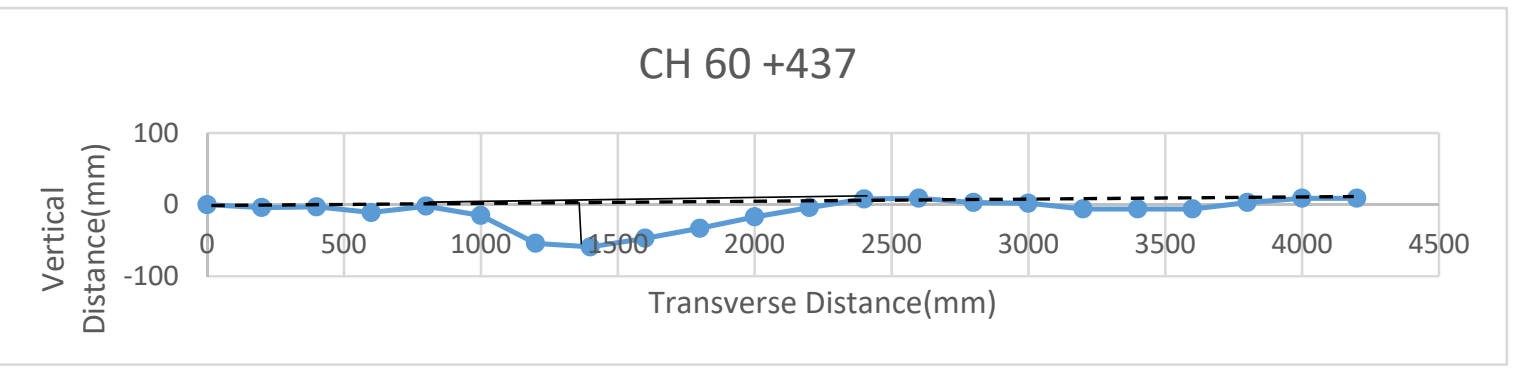

Figure 14. Transverse profile of $60+437 \mathrm{~km}$. 


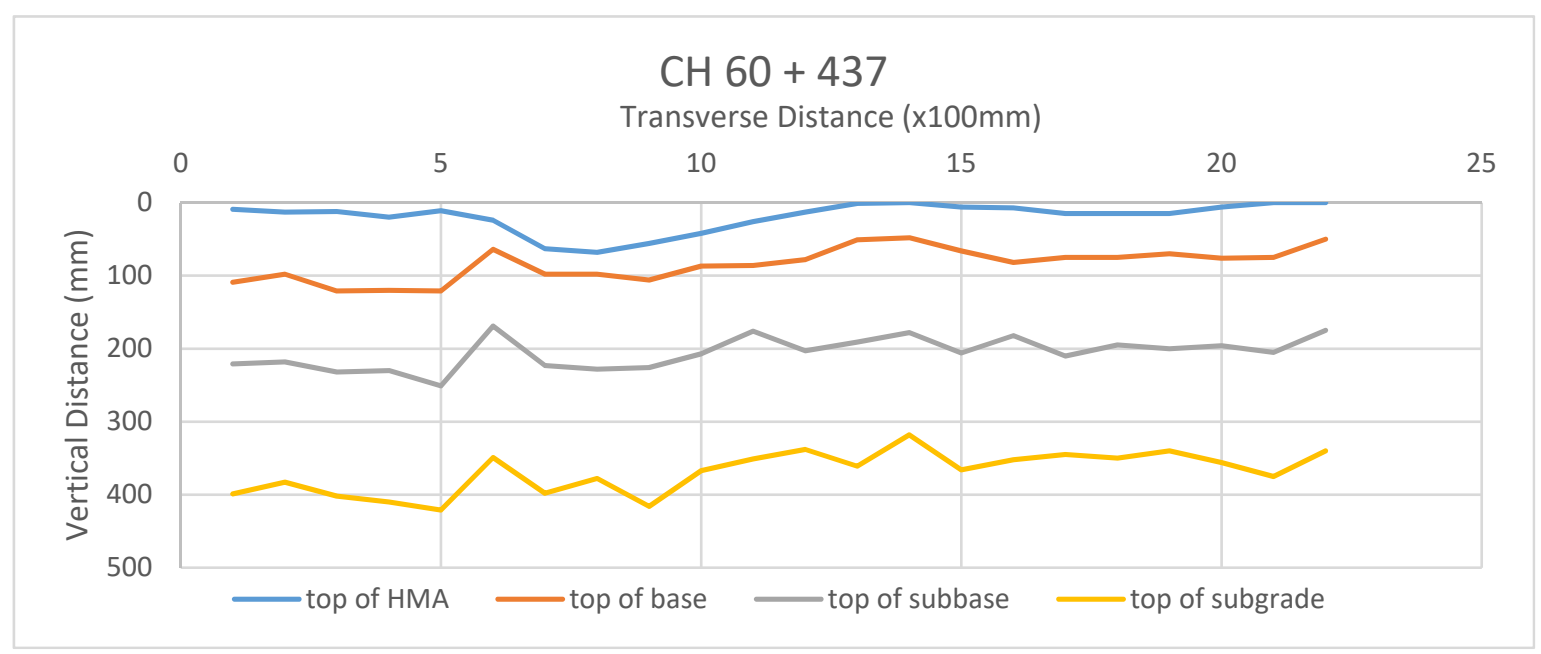

Figure 15. Profile of trench measurements of $60+437 \mathrm{~km}$.

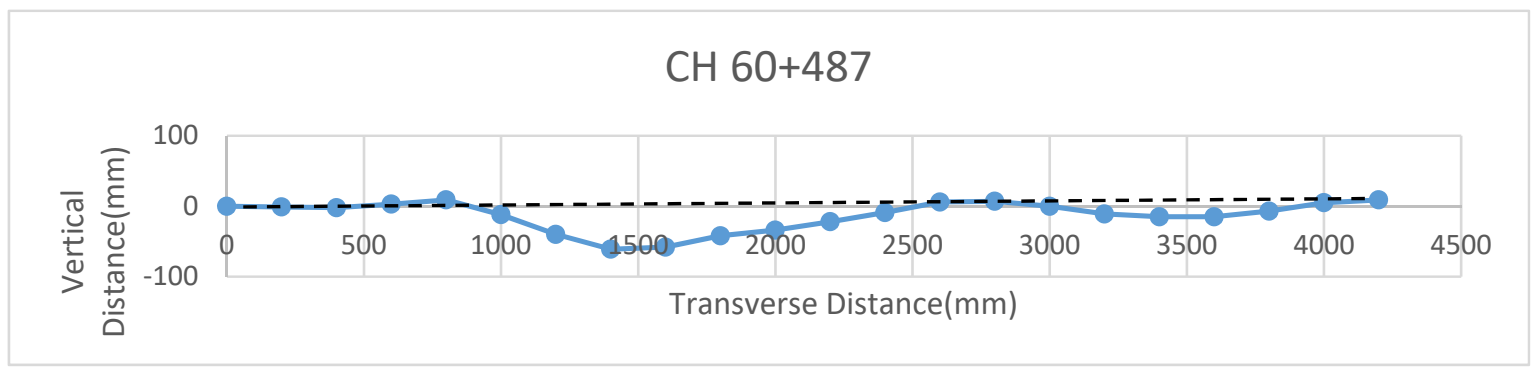

Figure 16. Transverse profile of $60+487 \mathrm{~km}$.

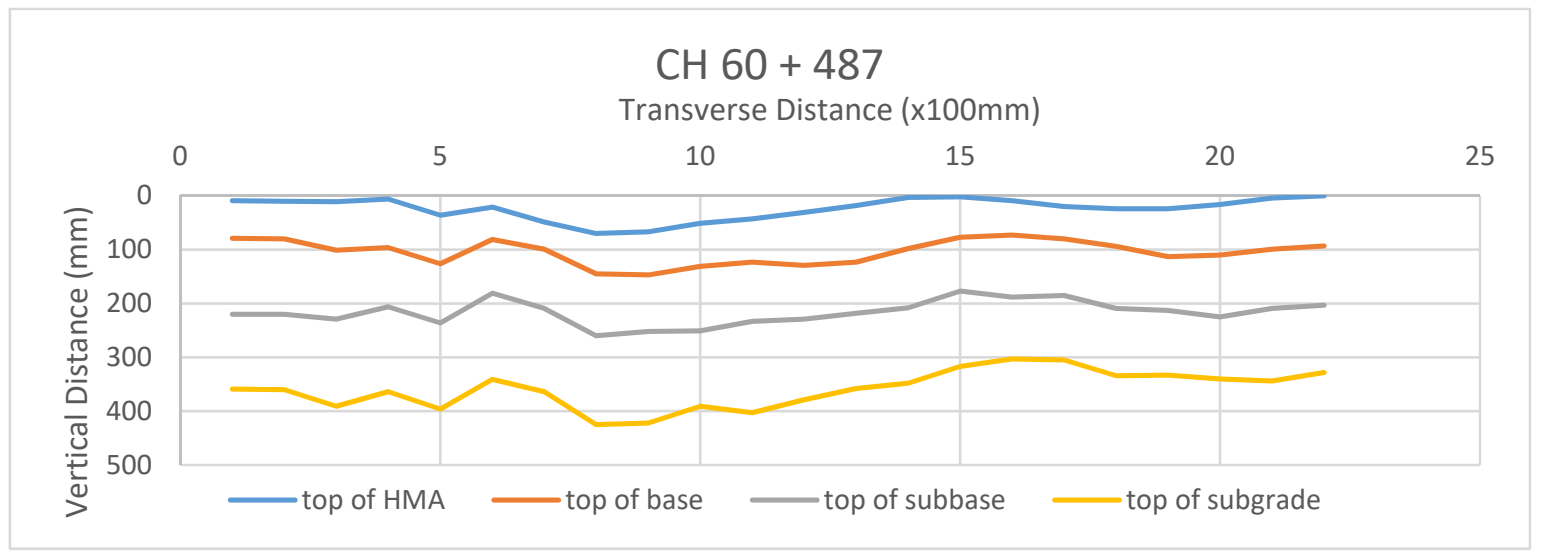

Figure 17. Profile of trench measurements of $60+487 \mathrm{~km}$.

From the profiles it is evident that the rutting at $60+365 \mathrm{~km}$ and $60+427 \mathrm{~km}$ resulted from within the asphalt surfacing. This is evidenced by the shoving and upheaval of the asphalt, which is clearly visible in Figures 10 and 12. It can also be seen from Figures 11 and 13 that the profile of the top of the asphalt surfacing is different from that of the top of the base, subbase and subgrade.

The profiles at $60+437 \mathrm{~km}$ and $60+487 \mathrm{~km}$, on the other hand, show that the underlying layers are responsible for the rutting failure. The asphalt profile is almost equivalent to the underlying layers and there is little to no shoving and/or upheaval of the asphalt.

The TPAM was undertaken to verify these observations. Distortion parameters where determined and calculated as outlined in Section 2. For example, for profile Chainage $(\mathrm{CH}) 60+365$; 
$\mathrm{A}_{\mathrm{p}}=35,963 \mathrm{~mm}^{2}$,

$\mathrm{A}_{\mathrm{n}}=-12,563 \mathrm{~mm}^{2}$,

$\mathrm{D}=64 \mathrm{~mm}$.

Total area $(\mathrm{A})$ :

Ratio of Area (R):

$$
A=A_{p}+A_{n}=35,963+(-12,563)=23,400 \mathrm{~mm}^{2} .
$$

$$
R=\left|A_{p} / A_{n}\right|=2.8626
$$

Calculate critical coefficients by Equations (3)-(5).

$$
\begin{aligned}
& \mathrm{C}_{1}=(-858.21)^{*} 64+667.58=-54,257.9 \mathrm{~mm}^{2}, \\
& C_{2}=(-1509)^{*} 64-287.78=-96,863.8 \mathrm{~mm}^{2}, \\
& C_{3}=(-2120)^{*} 64-407.95=-13,6094 \mathrm{~mm}^{2} .
\end{aligned}
$$

First check is applied by using Equations (6) and (7);

$$
\begin{array}{llc} 
& \mathrm{R}=2.8626>0.05 & \checkmark \text { checked } \\
\text { for } & \mathrm{A}=23,400 \mathrm{~mm}^{2} . & \\
\text { and } & \left(\mathrm{C}_{1}+\mathrm{C}_{2}\right) / 2=(-54,257.9-96,863.8) / 2=-75,560.85 \mathrm{~mm}^{2}, \\
\text { thus } & \mathrm{A}>\left(\mathrm{C}_{1}+\mathrm{C}_{2}\right) / 2 & \checkmark \text { checked }
\end{array}
$$

\begin{tabular}{|c|c|c|c|c|c|c|c|c|c|}
\hline \multicolumn{10}{|c|}{ Failed Layer Prediction from Transverse Profile Analysis } \\
\hline $\begin{array}{c}\text { Road } \\
\text { Name/Chainage }\end{array}$ & $\underset{\left(\mathrm{mm}^{2}\right)}{\mathrm{A}}$ & $\begin{array}{c}A_{p} \\
\left(\mathrm{~mm}^{2}\right)\end{array}$ & $\begin{array}{c}A_{n} \\
\left(m^{2}\right)\end{array}$ & $\mathbf{R}$ & $\begin{array}{c}\mathrm{C}_{1} \\
\left(\mathrm{~mm}^{2}\right)\end{array}$ & $\begin{array}{c}\mathrm{C}_{2} \\
\left(\mathrm{~mm}^{2}\right)\end{array}$ & $\begin{array}{c}\mathrm{C}_{3} \\
\left(\mathrm{~mm}^{2}\right)\end{array}$ & $\begin{array}{c}\mathrm{D} \\
(\mathrm{mm})\end{array}$ & $\begin{array}{l}\text { Failed } \\
\text { Layer }\end{array}$ \\
\hline \multicolumn{10}{|c|}{ Kitwe-Ndola Road } \\
\hline CH $60+365$ & 23,400 & 35,963 & 12,563 & 2.863 & $-54,257.9$ & $-96,863.8$ & $-136,094$ & 64 & HMA \\
\hline $\mathrm{CH} 60+427$ & $-13,800$ & 16,075 & 29,875 & 0.538 & $-41,384.7$ & $-74,228.8$ & $-104,293$ & 49 & HMA \\
\hline $\mathrm{CH} 60+437$ & $-61,785$ & 882 & 62,667 & 0.0143 & $-47,392.2$ & $-84,791.8$ & $-119,134$ & 56 & BASE \\
\hline $\mathrm{CH} 60+487$ & $-78,995$ & 1370 & 80,365 & 0.0173 & $-56,832.5$ & $-101,391$ & $-142,455$ & 67 & BASE \\
\hline
\end{tabular}

\begin{tabular}{|c|c|c|c|c|c|c|}
\hline \multicolumn{7}{|c|}{ KITWE-NDOLA ROAD } \\
\hline Chainage & $A\left(\mathrm{~mm}^{2}\right)$ & $\mathbf{R}$ & $\mathrm{D}(\mathrm{mm})$ & $\begin{array}{c}\text { Failed Layer } \\
\text { (Transverse Profile } \\
\text { Analysis) }\end{array}$ & $\begin{array}{l}\text { Failed Layer } \\
\text { (Trenching } \\
\text { Method) }\end{array}$ & Agreement \\
\hline $\mathrm{CH} 60+365$ & 23,400 & 2.863 & 64 & HMA & HMA & YES \\
\hline $\mathrm{CH} 60+427$ & $-13,800$ & 0.538 & 49 & HMA & HMA & YES \\
\hline $\mathrm{CH} 60+437$ & $-61,785$ & 0.0143 & 56 & BASE/SUBBASE & BASE/SUBBASE & YES \\
\hline $\mathrm{CH} 60+487$ & $-78,995$ & 0.0173 & 67 & BASE/SUBBASE & BASE/SUBBASE & YES \\
\hline
\end{tabular}

Both criteria were met, indicating that the failure occurred in the asphalt surfacing.

The procedure was repeated for all the profiles on the road (Table 2). It was established that at $60+365 \mathrm{~km}$ and $60+427 \mathrm{~km}$ the rutting was in the asphalt while at $60+437 \mathrm{~km}$ and $60+487 \mathrm{~km}$ the rutting emanated from the underlying base/subbase. This is consistent with the observed profile shape.

Table 2. Kitwe-Ndola Road profile analysis.

The results of the profile analysis were compared to measurements from the trenching. The results showed consistency between the two methods (Table 3).

Table 3. Comparison of trench measurements vs. profile analysis.

\subsection{Chibuluma and Kitwe-Chingola Roads}

After the validation, the profile analysis was conducted on sections of the Chibuluma and Kitwe-Chingola Roads. The results are shown in Tables 4 and 5, respectively. 
Table 4. Chibuluma Road profile analysis.

\begin{tabular}{|c|c|c|c|c|c|c|c|c|c|}
\hline \multicolumn{10}{|c|}{ Failed Layer Prediction from Transverse Profile Analysis } \\
\hline $\begin{array}{c}\text { Road } \\
\text { Name/Chainage }\end{array}$ & $\underset{\left(\mathrm{mm}^{2}\right)}{\mathrm{A}}$ & $\underset{\left(\mathrm{mm}^{2}\right)}{\mathrm{A}_{\mathrm{p}}}$ & $\begin{array}{c}\mathbf{A}_{\mathrm{n}} \\
\left(\mathrm{mm}^{2}\right)\end{array}$ & $\mathbf{R}$ & $\begin{array}{c}\mathrm{C}_{1} \\
\left(\mathrm{~mm}^{2}\right)\end{array}$ & $\begin{array}{c}\mathrm{C}_{2} \\
\left(\mathrm{~mm}^{2}\right)\end{array}$ & $\begin{array}{c}\mathrm{C}_{3} \\
\left(\mathrm{~mm}^{2}\right)\end{array}$ & $\underset{(\mathrm{mm})}{\mathrm{D}}$ & $\begin{array}{l}\text { Failed } \\
\text { Layer }\end{array}$ \\
\hline \multicolumn{10}{|c|}{ Chibuluma Road } \\
\hline $\mathrm{CH} 0+880$ & $-37,100$ & 8275 & 45,375 & 0.1824 & $-43,959.3$ & $-78,746.8$ & $-110,653$ & 52 & HMA \\
\hline $\mathrm{CH} 0+895$ & 17,200 & 36,255 & 19,055 & 1.9027 & $-51,683.2$ & $-92,327.8$ & $-129,734$ & 61 & HMA \\
\hline $\mathrm{CH} 0+910$ & 8775 & 23,950 & 15,175 & 1.5783 & $-41,384.7$ & $-74,219.8$ & $-104,293$ & 49 & HMA \\
\hline $\mathrm{CH} 0+925$ & 34,499 & 38,344 & 3845 & 9.9724 & $-41,384.7$ & $-74,219.8$ & $-104,293$ & 49 & HMA \\
\hline $\mathrm{CH} 0+940$ & 35,300 & 62,213 & 26,913 & 2.3116 & $-57,690.7$ & $-10,2891$ & $-144,575$ & 68 & HMA \\
\hline $\mathrm{CH} 1+655$ & -4900 & 35,503 & 40,403 & 0.8787 & $-48,250.4$ & $-86,291.8$ & $-121,254$ & 57 & HMA \\
\hline $\mathrm{CH} 1+670$ & -4600 & 28,568 & 33,168 & 0.8613 & $-38,810.1$ & $-69,692.8$ & $-97,932.6$ & 46 & HMA \\
\hline $\mathrm{CH} 1+685$ & 25,600 & 46,101 & 20,501 & 2.2487 & $-39,668.3$ & $-71,201.8$ & $-100,053$ & 47 & HMA \\
\hline $\mathrm{CH} 1+700$ & 24,676 & 40,656 & 15,980 & 2.5442 & $-45,675.8$ & $-81,764.8$ & $-114,893$ & 54 & HMA \\
\hline $\mathrm{CH} 1+715$ & 23,300 & 40,653 & 17,353 & 2.3427 & $-43,101.1$ & $-77,237.8$ & $-108,533$ & 51 & HMA \\
\hline
\end{tabular}

Table 5. Kitwe-Chingola Road profile analysis.

\begin{tabular}{|c|c|c|c|c|c|c|c|c|c|}
\hline \multicolumn{10}{|c|}{ Failed Layer Prediction from Transverse Profile Analysis } \\
\hline $\begin{array}{c}\text { Road } \\
\text { Name/Chainage }\end{array}$ & $\underset{\left(\mathrm{mm}^{2}\right)}{\mathrm{A}}$ & $\underset{\left(\mathrm{mm}^{2}\right)}{\mathbf{A}_{\mathrm{p}}}$ & $\begin{array}{c}A_{n} \\
\left(m^{2}\right)\end{array}$ & $\mathbf{R}$ & $\begin{array}{c}\mathrm{C}_{1} \\
\left(\mathrm{~mm}^{2}\right)\end{array}$ & $\begin{array}{c}\mathrm{C}_{2} \\
\left(\mathrm{~mm}^{2}\right)\end{array}$ & $\begin{array}{c}\mathrm{C}_{3} \\
\left(\mathrm{~mm}^{2}\right)\end{array}$ & $\begin{array}{c}\mathrm{D} \\
(\mathrm{mm})\end{array}$ & $\begin{array}{l}\text { Failed } \\
\text { Layer }\end{array}$ \\
\hline \multicolumn{10}{|c|}{ Kitwe-Chingola Road } \\
\hline $\mathrm{CH} 2+220$ & -2363 & 56,200 & 58,563 & 0.9597 & $-129,780$ & $-229,647$ & $-322,663$ & 152 & HMA \\
\hline $\mathrm{CH} 2+235$ & -3400 & 54,559 & 88,559 & 0.6161 & $-137,504$ & $-243,228$ & $-3,417,044$ & 161 & HMA \\
\hline $\mathrm{CH} 2+250$ & $-47,001$ & 23,339 & 70,340 & 0.3318 & $-99,743$ & $-176,832$ & $-248,460$ & 117 & HMA \\
\hline $\mathrm{CH} 2+265$ & $-21,400$ & 33,698 & 55,098 & 0.6116 & $-92,019.1$ & $-163,251$ & $-229,379$ & 108 & HMA \\
\hline $\mathrm{CH} 2+280$ & 29,400 & 34,706 & 5306 & 6.5409 & $-35,806.4$ & $-64,411.3$ & $-90,512.2$ & 42.5 & HMA \\
\hline $\mathrm{CH} 2+295$ & 13,600 & 16,468 & 2868 & 5.7421 & $-15,638.4$ & $-28,949.8$ & $-40,689.9$ & 19 & HMA \\
\hline $\mathrm{CH} 2+310$ & 32,000 & 41,851 & 9851 & 4.2484 & $-28,511.6$ & $-51,584.8$ & $-72,491.4$ & 34 & HMA \\
\hline $\mathrm{CH} 2+325$ & -7800 & 19,743 & 27,543 & 0.7168 & $-41,384.7$ & $-74,219.8$ & $-104,293$ & 49 & HMA \\
\hline $\mathrm{CH} 2+340$ & 7400 & 23,487 & 16,087 & 1.46 & $-27,635.4$ & $-50,075.8$ & $-70,371.3$ & 33 & HMA \\
\hline $\mathrm{CH} 2+355$ & 1454 & 15,970 & 14,516 & 1.1002 & $-32,802.6$ & $-59,129.8$ & $-83,091.9$ & 39 & HMA \\
\hline
\end{tabular}

\section{Discussion}

Results indicated that in all cases, the ratio of area $(\mathrm{R})$ was greater than 0.05 (the limit between HMA and base/subbase failure). This is an indication of the profiles having significant positive areas. It was also determined that the total area (A) was significantly greater than the combination of the critical coefficients $\left(\left(C_{1}+C_{2}\right) / 2\right)$, as shown in Tables 4 and 5 for Chibuluma and Kitwe-Chingola Roads, respectively. This meets both criteria for HMA failure and thus indicates that the asphalt was mainly responsible for the rutting failure. These results are consistent with the observed shape of the rutted road sections which were relatively deeply depressed and accompanied by upheavals along the sides of the wheelpath. The results are also consistent with recent research suggesting that rutting mainly occurs in the asphalt (surfacing) layer.

These results are an indication of inadequacy in the performance of the asphalt. Zambia, like most developing countries, is still using empirical pavement design methods whose focus is mostly on protecting the subgrade, thus leaving rutting to be assessed during the mix design of the asphalt. The results therefore call for particular attention to be paid to the asphalt mix design and construction in order to avoid/minimize this problem. Some of the measures that should be considered, as suggested in the literature as well, include:

1. Mix design method: The Marshall mix design method used in empirical designs has proven to be unsuitable for present day traffic, as evidenced by the steady increase in rutting problems [2]. A study by Verhaeghe et al. [16] suggested that the Marshall mix design method can be used for lower traffic or non-rut potential situations, but for high traffic or rut potential situations, gyratory-based design methods should be used, possibly coupled with performance tests. 
2. Bitumen binder: A higher bitumen content is needed for improved fatigue life and durability of the asphalt mix, but it tends to enhance the rutting and shoving problems. Therefore, the mix needs to be maximized for fatigue and permanent deformation through a compromise. It has also been established that bitumen binder with a high viscosity at $60^{\circ} \mathrm{C}$ will be more resistant to horizontal thrust as far as plastic flow in a mix is concerned, as compared to a low viscosity bitumen binder [17].

3. Gradations: An increase in the -75 microns fraction of the mix will tend to stiffen (increase the viscosity) the binder. However, finer gradations or over sanded mixes are more susceptible to permanent deformation than coarser gradations. Therefore, a compromise needs to be reached on the quantity of fine particles in the mix. It has also been demonstrated that mixtures utilizing angular manufactured sand and fine aggregates are more resistant to permanent deformation than mixes produced with rounded or sub-rounded natural sand. Larger-size aggregates (such as $19.5 \mathrm{~mm}$ ) mixed in the wearing course also tend to be more resistant to rutting [17,18].

4. Air void content: Mixtures with low voids in the mineral aggregate (VMA) and higher bitumen contents tend to have very low air void contents after densification by traffic. Low air voids result in a loss of mixture stability and rutting due to the buildup of pore pressure in the asphalt mixture under traffic loading, thus leading to loss of strength and flow [19].

5. Improved bond between pavement layers: The authors of [20] conducted FEM simulations to determine the effect of bonding between pavement layers and rutting. It was concluded that a good bond between the pavement layers was essential in minimizing rutting failure in road pavements.

6. Construction: One of the main causes of accelerated rut development, especially when the asphalt mat is still fresh, is insufficient compaction at the time of construction, which not only would result in higher levels of consolidation under traffic, but also could render the mix more susceptible to shear deformation in the early life of the HMA layer. Hence, during construction every attempt should be made to meet the density specifications of HMA. For continuously graded mixes, minimum density specifications are usually set at $93 \%$ of the maximum theoretical relative density (MTRD) [16].

\section{Conclusions}

Rutting failure is a common problem on most Zambian roads. The determination of which of the pavement layers is responsible for the failure is the first step in remediating the problem. The objective of this study was to determine the source of rutting failure in some selected sections of road using the TPAM.

It was established on both Chibuluma Road and Kitwe-Chingola Road that rutting failure mostly emanated from the surfacing layers. This is consistent with the observed shape of the rutted sections. The sections of the Kitwe-Ndola Road analyzed indicated a half split with two sections indicating HMA failure and the other two indicating base/subbase failure.

It was also established that the TPAM is an effective way of determining the pavement layer(s) responsible for rutting failure. The method showed very good comparability with the trench method. This indicates that the inferences made in the TPAM criteria are consistent with the traditional methods of rutting failure determination and can therefore perform the same function.

The TPAM is simple and less time consuming than traditional methods. A task which would have taken at least a couple of days was completed within a matter of a few hours. There was also less disturbance to traffic and, most importantly, the proposed method eliminated the need for expensive destructive testing. This tool will therefore be invaluable to road agencies, particularly in developing countries.

Author Contributions: Conceptualization, N.C.; Investigation, N.C. and R.L.; Project administration, N.C.; Supervision, N.C.; Writing—original draft, R.L.; Writing—review \& editing, N.C. 
Funding: This research received no external funding.

Conflicts of Interest: The authors declare no conflict of interest.

\section{References}

1. Road Development Agency. Road Condition Report; Road Development Agency: Lusaka, Zambia, 2014.

2. Mwanza, A.D. Modelling of Rutting Prediction for Flexible Pavements in Zambia. Ph.D. Thesis, Chang'an University, Xi'an, China, 2008.

3. Schwartz, C.W.; Carvalho, L.R.; Von Quintus, H.L.; Mallela, J.; Bonaquist, R. Calibration of Rutting Models for HMA Structural and Mixture Design-Appendix K: Advanced Materials Characterization and Modeling; Transportation Research Board: Washington, DC, USA, 2012. [CrossRef]

4. Serigos, P.A.; Murphy, M.; Prozzi, J.A. Evaluation of Rut-Depth Accuracy and Precision Using Different Automated Systems for Texas Conditions; TRB: Washington, DC, USA, 2013; pp. 13-117. Available online: https: //pdfs.semanticscholar.org/336f/faf6a5d3342795f99cf586b5670403d5bd41.pdf (accessed on 13 January 2019).

5. American Association of State Highway and Transportation Officials. Mechanistic-Empirical Pavement Design Guide: A Manual of Practice, Interim edition; American Association of State Highway and Transportation Officials: Washington, DC, USA, July 2008; p. 212. Available online: https:/fenix.tecnico.ulisboa.pt/ downloadFile/563568428712666/AASHTO08.pdf (accessed on 27 December 2018).

6. Sethi, K.C.; Sangita; Tiwari, D.; Baral, D. Investigation on the Causes of Failure in Flexible Pavements. In Proceedings of the International Conference on Engineering Science and Management, Goa, India, 17-18 December 2016; p. 264.

7. White, T.D.; Haddock, J.E.; Hand, A.J.T.; Fang, H. Contributions of Pavement Structural Layers to Rutting of Hot Mix Asphalt Pavements; (NCHRP report No. 468); Transport Res Board, National Academy Press: Washington, DC, USA, 2002; Available online: http://onlinepubs.trb.org/onlinepubs/nchrp/nchrp_rpt_468-a. pdf (accessed on 27 December 2018).

8. Ogundipe, O.M. Marshall Stability and Flow of Lime-Modified Asphalt Concrete. Transp. Res. Arena 2016, 14, 685-693. [CrossRef]

9. Garba, R. Permanent Deformation Properties of Asphalt Concrete Mixtures. Ph.D. Thesis, Department of Road and Railway Engineering, Norwegian University of Science and Technology, Trondheim, Norway. 28 June-2 July 2002.

10. Simpson, A.L. Characterization of Transverse Profile. Transp. Res. Rec. 1999, 1655, 185-191. [CrossRef]

11. Lenngren, C.A. Some Approaches in Treating Automatically Collected Data on Rutting. In Transportation Research Record: Journal of the Transportation Research Board; No. 11 96; Transportation Research Board of the National Academies: Washington, DC, USA, 1988; pp. 20-26. ISBN 0309047714.

12. Villiers, C.; Roque, R.; Dietrich, B. Interpretation of Transverse Profiles to Determine the Source of Rutting within an Asphalt Pavement System. Transp. Res. Rec. 2005, 1905, 73-81. [CrossRef]

13. Hussan, S.; Kamal, M.A.; Khan, M.B.; Irfan, M.; Hafeez, I. Determining the Contribution of Different Structural Layers of Asphalt Pavement System to Rutting Using Transverse Profile Analysis. Am. J. Civ. Eng. Archit. 2013, 1, 174-180. [CrossRef]

14. Solyman, M.; Salama, H. Field Investigation of Flexible Pavement Rutting Damage Using the Transverse Surface Profile. J. Am. Sci. 2012. Available online: http://www.jofamericanscience.org/journals/am-sci/ am0808/007_9834am0808_44_50.pdf (accessed on 27 December 2018).

15. Haddock, J.E.; Hand, A.J.T.; Fang, H.; White, T.D. Determining Layer Contributions to Rutting by Surface Profile Analysis. J. Transp. Eng. 2005, 131, 131-139. [CrossRef]

16. Verhaeghe, B.M.J.A.; Myburgh, P.A.; Denneman, E. Asphalt Rutting and its prevention. In Proceedings of the 9th Conference on Asphalt Pavements in Southern Africa, Gaborone, Botswana, 2-5 September 2007; Available online: http://hdl.handle.net/10204/1241 (accessed on 18 April 2019).

17. Mahan, H.M. Behavior of Permanent Deformation in Asphalt Concrete Pavements under Temperature Variation, Al-Qadisiya. J. Eng. Sci. 2013, 6, 62-73.

18. Kandhal, P.S.; Mallick, R.B.; Brown, E.R. Hot Mix Asphalt for Intersection in Hot Climates; Presented at the NCAT Report 98-06; National Center for Asphalt Technology, Auburn University: Auburn, AL, USA, 1998.

19. Lushinga, N.; Jiang, X. Effect of Horizontal Shear Load on Pavement Performance. In Proceedings of the 2nd International Conference on Geological and Civil Engineering, Singapore, 13-14 March 2015. 
20. Aluga, M. Finite Element Modelling of Rutting Failure of Flexible Pavements. Master's Thesis, Science in Engineering, Copperbelt University, Kitwe, Zambia, 2016. (CC BY) license (http://creativecommons.org/licenses/by/4.0/). 